Assiut Scientific Nursing Journal

http://asnj.journals.ekb.eg

http://www.arabimpactfactor.com

\title{
Effect of Applying Postoperative Nursing Instructions OnAnkle Open Reduction Internal Fixation Surgery Patients.
}

\author{
Neama Mamdouh Mostafa ${ }^{1}$ \& Ahmed Ekram Osman ${ }^{2}$. \\ ${ }^{1}$ Medical-Surgical Nursing, Faculty of Nursing, Assiut University, Egypt. \\ 2. Orthopedic surgery, Faculty of Medicine, Assiut University, Egypt.
}

\begin{abstract}
Background: Fractures of the ankle are one of the most common lesions the orthopedic surgeon handles. Aim: to evaluate the effect of applying postoperative nursing instructions on ankle open reduction internal fixation (ORIF) surgery patients. Research design: Quasi experimental research design was utilized in this study. Setting: This study was performed in trauma units (male and female) and orthopedic clinic at Assiut University Hospital. Sample: This study included a convenient sample of (60 patients). Tool I: Interview questionnaire sheet Tool II: Patient complications assessment sheet. Results: In lateral wound it was found that one quarter of control group had normal healing while more than two fifth in study group. In medial wound healing it was found that more than one third of control group had normal healing while majority in study group. Conclusion: The present study revealed that providing patients with post-operative nursing instructions were represented of great value in wound healing and reduction other complications (residual pain, Malunion, infection, deformity). Recommendations: the present study should be replicated on larger study populations for generalization of the results.
\end{abstract}

\section{Keywords: Ankle Fractures, Internal Fixation Surgery \& Nursing Instructions.}

\section{Introduction}

The ankle joint is the fusion of three bony structures. Those are the talus tibia distal ends, the fibula and the talus trochlea. In the ankle joint fork, the tibia and fibula are elastically connected by the syndesmose ligament structures (interosseous membrane; anterior, posterior, and transverse tibiofibular ligaments) (Todd, 2015).

Ankle fractures, varying in severity from stable lateral malleolus fractures to open fracture dislocations with commination, are the most common fractures requiring surgical treatment (Mikko, 2016). Ankle fractures are increasingly common injuries that necessitate a careful approach for proper management. More than five million ankle injuries happen annually in the United States (Van den berg et al., 2018).

Ankle fractures are among the most common lower limb fractures which account for $10 \%$ of all fractures, representing a significant portion of the trauma workload. Nevertheless, usually affect young men and older women below 50 years of age; ankle fractures are the commonest in men. After this age, females become predominant (Juto, 2018).

Twisting lesions and falls are the most common causes of ankle fractures, followed by sports injuries. Alcohol and slippery surfaces are involved in almost a third of each case (Unnithan \& Thomas, 2018). Surgical treatment means reduction if the fractured parts are displaced and fixed using different devices such as metal plates, screws, tension bands or external trying to fix. These operating techniques aim at restoring anatomy and ensuring immediate stabilization, which promotes earlier mobilization (David, 2019).

The timing of effective surgical treatment depends largely on the soft tissue findings. Immediate definite surgery is possible only with highly fragile soft tissues. Surgery should be postponed in all other situations until inflammation around the joint has subsided, and wrinkles in the skin have reappeared. When surgery is carried out while the soft tissue is still swollen, this may be technical impossible to close the wound without excessive tension. (David \& Naomi, 2019)

Several complications may accompany surgical treatment of ankle fractures the overall complication rate following ankle fractures ORIF The literature varies considerably from $1 \%$ to $40 \%$. Postoperative guidance may reduce the incidence of surgical complications. Complications of postoperative wounds are the most common problems, of which deep infection the may have the most devastating consequences (Macera et al., 2018).

The most common complications following ankle fracture surgery are infection with the surgical site (SSI). The incidence of SSI following operative treatment of ankle fractures ranging from $1.4 \%$ to $5.5 \%$, and infection rates as high as $19 \%$ have been reported in diabetic patients (Sun et al., 2018 ) . 
Certain documented complications include deficient primary osteosynthesis, soft tissue necrosis, inflammation, osteitis, DVT, delayed union, nonunion, secondary displacement, refracture, stiffness, muscle atrophy, tendinal insufficiency, sensory impairment, tarsal tunnel syndrome and Type 1 complex regional pain syndrome type 1 (Mehta et al., 2014 ).

Post-operative nursing instructionsis a major factor in the success of surgeryas well as reducing the incidence of complications after surgery. Patients are taught a home nursing guidelinesfor each component. (Nursing Alliance for Quality of Care, 2013).

\section{Significance of the study}

Ankle joint fractures are among the most common adult fractures with an occurrence of up to 187 cases per 100000 people per year (Kortekangas et al.,2019).During the year 2019, 135 cases were reported and diagnosed as ankle fracture, according to trauma unit records at Assiut University Hospital

\section{Operational definition}

- Nursing instructions: It refers to the advices or teaching and guidance that are provided by the professional nurse and must be followed by the patient regarding improving knowledge

- Ankle Open Reduction Internal Fixation Surgery: is atype of surgery used to stabilize and heal a broken bone. It used to treat broken ankle.

\section{Aim of the study}

The research aimed to evaluate the effect of applying postoperative nursing instructionsonankle open reduction internal fixation surgery patients.

\section{Hypothesis}

The ankle open reduction internal fixation surgery patients will be improved after applying postoperative nursing instructions.

\section{Subjects \& Method \\ Research design}

This study utilized quasi experimental research design.

\section{Setting:}

The study was conducted in trauma units and orthopedic clinic at Assiut University Hospital

\section{Subjects}

A convenient sample of 60 adult patients (male and female), undergoing surgery (ORIF). Their ages varied between eighteen and sixty. The patients split into two equivalents study and control) the study group received the postoperative nursing instructions and control group received routine hospital care.

\section{Sample size}

The power analysis to estimate the sample size was performed based on the result of previous study. Assuming power of $0.80 \%$ and 0.05 (one sided equivalence test). A total sample size of 56 participants is required the patients were invited to participate after the assessment, they meet all of the inclusion criteria $\mathrm{n}=60$

Study tools:

Tool I: Interview questionnaire sheet: designed by the researcher based on current national and international literature, and composed of two parts:

Part (1): Patient demographics: it includes age, gender, marital status, educational level and occupation.

Part (2): Assessment of Patient'shistoryof trauma: it includes causes of fracture, date of fracture, dateof surgery, patient's diagnosis, involved side and chronic diseases.

Tool II: Assessment sheet for patient complications: The following parts were included

1. Skin and Neurovascular status of affected limb

2. Wound assessment scale scoring system for the lateral and medial wound site (Pudner, 2005). The wound was classified into one of four groups after 10-14 days of postoperative surgery: usual healing, minor complications, wound infection and major hematoma

\section{Scoring system}

With regard to the assessment of wound site infection, each item was detected, graded and rated to be present or not present on all items for study and control groups

3. Other complications that included Residual pain, Malunion, Deformity, Infection, deep venous thrombosis (DVT)and bleeding

Postoperative Nursing Instructions: It was prepared by the researchers based on reviewing recent literature and opinion of the medical and nursing expertise. It was designed in a simplified Arabic language and was supported by photo illustrations and colored pictures. It consists of the following:

A. Simple information about ankle fracture (definition, causes, signs and symptoms, conservative and surgical treatment) of ankle fracture.

B. Post-operative and follow up visits instructions.

1- Swelling and pain reduction method.

2- Proper Nutrition.

3- Nausea and vomiting.

4- Wound care.

5- Car driving.

6- Medications.

7- Warning signs and symptoms of complications.

8- Postoperative follow up

9- How to use cane.

10-Physical exercises.

- Ankle Range of Motion

- Shallow standing knee bends

- Straight leg raises

- Heel raises 


\section{Method \\ Ethical considerations}

The study was affirmed by ethics committee of faculty of nursing and from the hospital authorities of trauma units and outpatients clinics of orthopedic; a composed endorsement was gotten from the enlisted patients to take part within the study after clarifying the nature and reason of the study. The researcher explained that participation is voluntary, and that the status of patient involvement will not influence the treatment they will receive. The patients were allowed to refuse to take part in the research and can withdraw at any time.

\section{Procedure}

The study was performed in three phases

Preparatory phase

Tools development: A review of current and past, local and international related literature. Books, journals, periodicals and magazines were used in various aspects.

\section{Content validity and reliability}

It was established by a panel of five experts (three experts from Medical Surgical Nursing staff and two Orthopedic Surgery staff) who reviewed the tool for clarity, relevance, comprehensivity, understanding and applicability. Minor modifications were required. Contents reliability of the proposed tools was ascertained with Cronbach's alpha $=0.82$

\section{Pilot Study}

A pilot study was conducted during January 2019, on $10 \%$ of patientswho were included within the research to examine clarity, applicability and feasibility of the used tools; those patients were included in the main study as there was no modification needed in the study tool.

\section{Implementation Phase}

- At initial interview the researchers introduce themselves to initiate line of communication, explain the nature \& purpose of the study and fill out Interview questionnaire sheet (tool I).

- The researcher met each patient individually and described the study and its goals to the patient

- Postoperative nursing instructions had been implemented for patients withankle open reduction internal fixation surgery.

- For the study group; after filling the Interview questionnaire sheet, the researcher explained to the patient the nursing instructions postoperatively in the following sequence:

- The postoperative nursing instructions were administered to the patient in two sessions; the duration of each session was about half hour, including 15 minutes for discussion and feedback.

- The researchers in the first session explained to the patientssimple information about ankle fracture (definition ,causes, signs and symptoms, conservative and surgical treatment ) of ankle fracture

- Second session was specified for the postoperative nursinginstructions and exerciseswhich were demonstrated by the researcher to the patients.

- Copy of the postoperative nursing instructions was provided for each patient in the study group.

- For control group they receivedroutine hospital postoperative instructions.

- The researchers arranged with the patients the time and place for follow up which were after two weeks and four months in the out patients clinic of orthopaedic at Assiut University Hospital

- This study was carried out through the period from February 2019 to July 2019 at morning shift

Evaluation phase

Upon the patient's discharge from the hospital, the researcher approached the patient for follow-up in an outpatient orthopaedic clinic (during his / her first visit 2 weeks after the surgery and 4 months after the surgery) to re-evaluate the condition of the patient, this is for the members of the control and study group by using Tool II .

\section{Statistical analysis}

The data were verified for normality using the Anderson-Darling test and for homogeneity variances prior to further statistical analysis. Categorical variables were described by number and percent $(\mathrm{N}$, $\%$ ), where continuous variables described by mean and standard deviation (Mean, SD). Chi-square test and fisher exact test used to compare between categorical variables where compare between continuous variables by t-test. A two-tailed $\mathrm{p}<0.05$ was considered statistically significant. All analyses were performed with the IBM SPSS 20.0 software. 


\section{Results}

Table (1): Distribution of studied sample (both control and study groups) as regarding to their demographic characteristics.

\begin{tabular}{|c|c|c|c|c|c|}
\hline & \multicolumn{2}{|c|}{$\operatorname{Control}(n=30)$} & \multicolumn{2}{|c|}{$\operatorname{Study}(n=30)$} & \multirow{2}{*}{ P. value } \\
\hline & $\mathbf{N}$. & $\%$ & $\mathbf{N}$. & $\%$ & \\
\hline \multicolumn{6}{|l|}{ Age group } \\
\hline Less than 30 year & 11 & 36.7 & 5 & 16.7 & \multirow{3}{*}{0.197} \\
\hline from $30-40$ years & 4 & 13.3 & 4 & 13.3 & \\
\hline more than 40 year & 15 & 50.0 & 21 & 70.0 & \\
\hline Mean \pm SD & \multicolumn{2}{|c|}{$41.10 \pm 16.7$} & \multicolumn{2}{|c|}{$47.67 \pm 3.04$} & 0.085 \\
\hline \multicolumn{6}{|l|}{ Gender } \\
\hline Male & 26 & 86.7 & 22 & 73.3 & \multirow{2}{*}{0.197} \\
\hline Female & 4 & 13.3 & 8 & 26.7 & \\
\hline \multicolumn{6}{|l|}{ Marital Status } \\
\hline Single & 6 & 20.0 & 2 & 6.7 & \multirow{4}{*}{0.148} \\
\hline Married & 21 & 70.0 & 25 & 83.3 & \\
\hline Divorced & 0 & 0.0 & 2 & 6.7 & \\
\hline Widow or Widower & 3 & 10.0 & 1 & 3.3 & \\
\hline \multicolumn{6}{|l|}{ Level of education } \\
\hline High education & 1 & 3.3 & 1 & 3.3 & \multirow{5}{*}{0.342} \\
\hline Secondary education & 8 & 26.7 & 8 & 26.7 & \\
\hline Read and write & 5 & 16.7 & 6 & 20.0 & \\
\hline Illiterate & 14 & 46.7 & 8 & 26.7 & \\
\hline Primary education & 2 & 6.7 & 7 & 23.3 & \\
\hline \multicolumn{6}{|l|}{ Occupation } \\
\hline Employee & 8 & 26.7 & 4 & 13.3 & \multirow{4}{*}{0.231} \\
\hline Student & 2 & 6.7 & 0 & 0.0 & \\
\hline Farmer & 15 & 50.0 & 18 & 60.0 & \\
\hline House wife & 5 & 16.7 & 8 & 26.7 & \\
\hline
\end{tabular}

Chi-Square Tests Ns $=$ Non significant difference $P>0.05$ 
Table (2): Distribution of studied sample (both control and study groups) as regarding to medical data.

\begin{tabular}{|c|c|c|c|c|c|}
\hline & \multicolumn{2}{|c|}{$\operatorname{Control}(n=30)$} & \multicolumn{2}{|c|}{ Study $(n=30)$} & \multirow{2}{*}{ P. value } \\
\hline & $\mathbf{N}$. & $\%$ & $\mathbf{N}$. & $\%$ & \\
\hline \multicolumn{6}{|l|}{ Causes } \\
\hline Falls & 14 & 46.7 & 16 & 53.3 & \multirow{2}{*}{0.606} \\
\hline Accident & 16 & 53.3 & 14 & 46.7 & \\
\hline \multicolumn{6}{|l|}{ Affected Side } \\
\hline Right & 16 & 53.3 & 8 & 26.7 & \multirow{3}{*}{$0.022 *$} \\
\hline Left & 12 & 40.0 & 22 & 73.3 & \\
\hline Right and left & 2 & 6.7 & 0 & 0.0 & \\
\hline \multicolumn{6}{|l|}{ Chronic diseases } \\
\hline Diabetes Mellitus & 3 & 10.0 & 4 & 13.3 & 0.688 \\
\hline Hypertension & 0 & 0.0 & 9 & 30.0 & $0.001 * *$ \\
\hline Cardiovascular disease & 0 & 0.0 & 2 & 6.7 & 0.150 \\
\hline Pulmonary disease & 0 & 0.0 & 0 & 0.0 & - \\
\hline Kidney disease & 0 & 0.0 & 0 & 0.0 & - \\
\hline Endocrine disease & 0 & 0.0 & 0 & 0.0 & - \\
\hline Tumors disease & 0 & 0.0 & 0 & 0.0 & - \\
\hline \multicolumn{6}{|l|}{ Color } \\
\hline Pale & 9 & 30.0 & 14 & 46.7 & \multirow{3}{*}{$0.009 * *$} \\
\hline Cyanosed & 8 & 26.7 & 0 & 0.0 & \\
\hline Normal & 13 & 43.3 & 16 & 53.3 & \\
\hline \multicolumn{6}{|l|}{ Skin temperature } \\
\hline Hot & 17 & 56.7 & 0 & 0.0 & \multirow{2}{*}{$<0.001 * *$} \\
\hline Warm & 13 & 43.3 & 28 & 93.3 & \\
\hline \multicolumn{6}{|l|}{ Swelling } \\
\hline Marked & 5 & 16.7 & 2 & 6.7 & \multirow{3}{*}{0.349} \\
\hline Moderate & 21 & 70.0 & 21 & 70.0 & \\
\hline Nile & 4 & 13.3 & 7 & 23.3 & \\
\hline \multicolumn{6}{|l|}{ Pulse } \\
\hline Absent & 3 & 10.0 & 0 & 0.0 & \multirow{3}{*}{$0.029 *$} \\
\hline Weak & 25 & 83.3 & 20 & 66.7 & \\
\hline Strong & 2 & 6.7 & 8 & 26.7 & \\
\hline \multicolumn{6}{|l|}{ Capillary refill } \\
\hline Early & 9 & 30.0 & 24 & 80.0 & \multirow{2}{*}{$<0.001 * *$} \\
\hline Delayed & 21 & 70.0 & 6 & 20.0 & \\
\hline \multicolumn{6}{|l|}{ Neurostatus } \\
\hline Paralysis & 3 & 10.0 & 0 & 0.0 & \multirow{3}{*}{$<0.001 * *$} \\
\hline Pain & 27 & 90.0 & 14 & 46.7 & \\
\hline Parasthesia & 0 & 0.0 & 16 & 53.3 & \\
\hline
\end{tabular}

Chi-Square Tests *statistically significant difference at P. value $<0.05$, **statistically significant difference at P. value $<0.01$ 


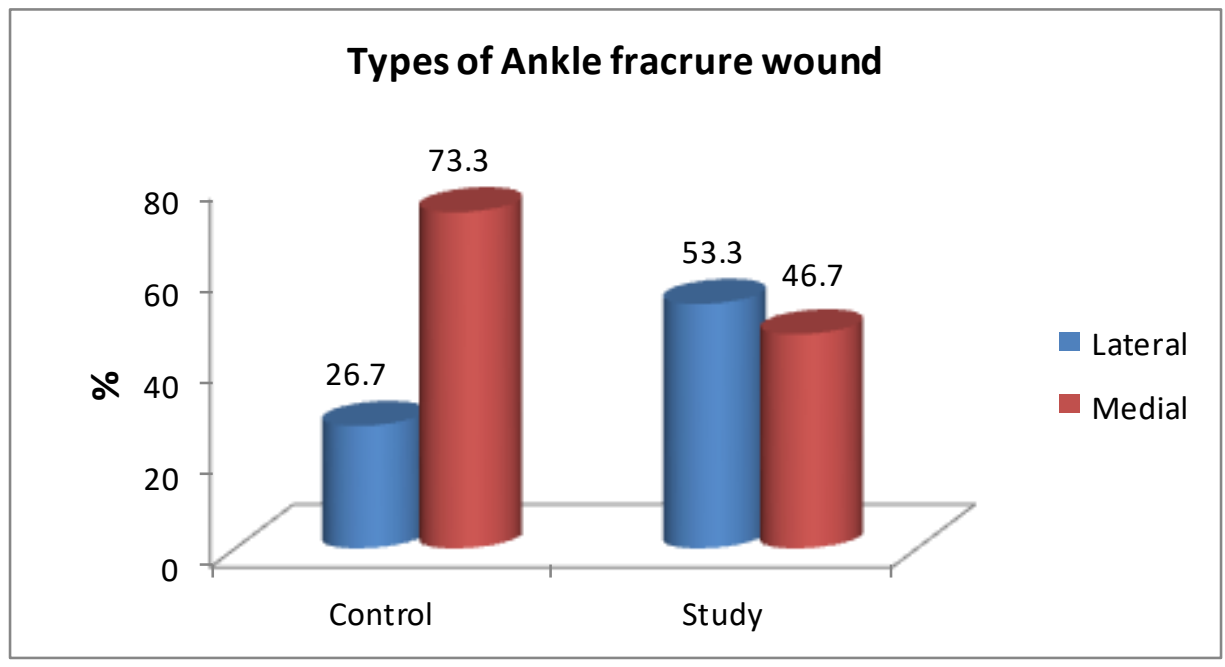

Figure (1): Percentages distribution of both groups (control and study group) according to type of ankle fracture wound.

Table (3): Comparison between Study and Control group as regard wound assessment scaleand other complications.

\begin{tabular}{|c|c|c|c|c|c|c|c|c|c|c|}
\hline & \multicolumn{4}{|c|}{ Lateral wound } & \multirow{3}{*}{ P. value } & \multicolumn{4}{|c|}{ Medial Wound } & \multirow{3}{*}{ P. value } \\
\hline & \multicolumn{2}{|c|}{ Control $(n=8)$} & \multicolumn{2}{|c|}{ Study $(n=16)$} & & \multicolumn{2}{|c|}{ Control $(n=22)$} & \multicolumn{2}{|c|}{ Study $(n=14)$} & \\
\hline & N. & $\%$ & $\mathbf{N}$. & $\%$ & & $\mathbf{N}$. & $\%$ & $\mathbf{N}$. & $\%$ & \\
\hline \multicolumn{5}{|l|}{ Grade and Appearance } & \multirow{6}{*}{0.092} & & & & & \multirow{6}{*}{$0.020 *$} \\
\hline Normal healing & 2 & 25.0 & 7 & 43.8 & & 8 & 36.4 & 12 & 85.7 & \\
\hline $\begin{array}{l}\text { Erythema plus others } \\
\text { sighs of inflammation }\end{array}$ & 4 & 50.0 & 4 & 25.0 & & 5 & 22.7 & 2 & 14.3 & \\
\hline $\begin{array}{c}\text { clear or heamoserous } \\
\text { discharge }\end{array}$ & 0 & 0.0 & 3 & 18.8 & & 2 & 9.1 & 0 & 0.0 & \\
\hline Major complication pus & 0 & 0.0 & 2 & 12.5 & & 7 & 31.8 & 0 & 0.0 & \\
\hline $\begin{array}{l}\text { Erythema plus others sighs } \\
\text { of inflammation clear or } \\
\text { heamoserous discharge }\end{array}$ & 2 & 25.0 & 0 & 0.0 & & 0 & 0.0 & 0 & 0.0 & \\
\hline Some bruising & - & - & - & - & - & - & - & - & - & - \\
\hline Considerable bruising & - & - & - & - & - & - & - & - & - & - \\
\hline Mild erythema & - & - & - & - & - & - & - & - & - & - \\
\hline At one point & - & - & - & - & - & 2 & 9.1 & 0 & 0.0 & 0.246 \\
\hline Around Suture & - & - & - & - & - & & & & & - \\
\hline Along wound & 4 & 50.0 & 2 & 12.5 & $0.046^{*}$ & 5 & 22.7 & 1 & 7.1 & 0.440 \\
\hline Around wound & 6 & 75.0 & 2 & 12.5 & $0.002 * *$ & 6 & 27.3 & 0 & 0.0 & $0.032 *$ \\
\hline At one Point only $(<2 \mathrm{~cm})$ & 5 & 62.5 & 3 & 18.8 & $0.032 *$ & 2 & 9.1 & 0 & 0.0 & 0.246 \\
\hline Along wound $(>2 \mathrm{~cm})$ & - & - & - & - & - & & & & & - \\
\hline large Volume & - & - & - & - & - & & & & & - \\
\hline Prolonged (>3 days) & - & - & - & - & - & & & & & - \\
\hline At one pints $(<2 \mathrm{~cm})$ & 0 & 0.0 & 2 & 12.5 & 0.296 & 3 & 13.6 & 0 & 0.0 & 0.149 \\
\hline Along wound $(>2 \mathrm{~cm})$ & - & - & - & - & - & 4 & 18.2 & 0 & 0.0 & 0.091 \\
\hline Along wound & - & - & - & - & - & & & & & \\
\hline \multicolumn{11}{|l|}{ Other complication } \\
\hline Residual Pain & 8 & 100 & 4 & 67 & \multirow{4}{*}{0.078} & 10 & 45.5 & 9 & 64.3 & \multirow{4}{*}{$0.035^{*}$} \\
\hline Malunion & 0 & 0.0 & 2 & 33 & & 2 & 9.1 & 0 & 0.0 & \\
\hline Deformity & 0 & 0.0 & 0 & 0.0 & & 4 & 18.2 & 0 & 0.0 & \\
\hline Infection & 0 & 0.0 & 0 & 0.0 & & 7 & 31.8 & 0 & 0.0 & \\
\hline
\end{tabular}

Chi-Square Tests * $*_{\text {statistically significant difference at } P \text {. value }<0.05}$ 
Table (4): Relation between Types of ankle fracture wound and demographic data for Study and Control group.

\begin{tabular}{|c|c|c|c|c|c|c|c|c|c|c|}
\hline \multirow{3}{*}{ Demographic data } & \multicolumn{5}{|c|}{ Control group } & \multicolumn{5}{|c|}{ Study group } \\
\hline & \multicolumn{2}{|c|}{ Lateral } & \multicolumn{2}{|c|}{ Medial } & \multirow{2}{*}{ P. value } & \multicolumn{2}{|c|}{ Lateral } & \multicolumn{2}{|c|}{ Medial } & \multirow{2}{*}{ P. value } \\
\hline & N. & $\%$ & N. & $\%$ & & $\mathbf{N}$. & $\%$ & N. & $\%$ & \\
\hline \multicolumn{11}{|l|}{ Age group } \\
\hline Less than 30 year & 2 & 25.0 & 9 & 40.9 & \multirow{3}{*}{0.468} & 3 & 18.8 & 2 & 14.3 & \multirow{3}{*}{0.944} \\
\hline from $30-40$ years & 2 & 25.0 & 2 & 9.1 & & 2 & 12.5 & 2 & 14.3 & \\
\hline more than 40 year & 4 & 50.0 & 11 & 50.0 & & 11 & 68.8 & 10 & 71.4 & \\
\hline \multicolumn{11}{|l|}{ Gender } \\
\hline Male & 7 & 87.5 & 19 & 86.4 & \multirow{2}{*}{0.935} & 14 & 87.5 & 8 & 57.1 & \multirow{2}{*}{0.061} \\
\hline Female & 1 & 12.5 & 3 & 13.6 & & 2 & 12.5 & 6 & 42.9 & \\
\hline \multicolumn{11}{|l|}{ Marital Status } \\
\hline Single & 2 & 25.0 & 4 & 18.2 & \multirow{4}{*}{0.531} & 2 & 12.5 & 0 & 0.0 & \multirow{4}{*}{0.177} \\
\hline Married & 6 & 75.0 & 15 & 68.2 & & 13 & 81.3 & 12 & 85.7 & \\
\hline Divorced & 0 & 0.0 & 0 & 0.0 & & 0 & 0.0 & 2 & 14.3 & \\
\hline Widow or Widower & 0 & 0.0 & 3 & 13.6 & & 1 & 6.3 & 0 & 0.0 & \\
\hline \multicolumn{11}{|l|}{ Level of education } \\
\hline High education & 1 & 12.5 & 0 & 0.0 & \multirow{5}{*}{0.311} & 0 & 0.0 & 1 & 7.1 & \multirow{5}{*}{0.184} \\
\hline Secondary education & 1 & 12.5 & 7 & 31.8 & & 5 & 31.3 & 3 & 21.4 & \\
\hline Read and write & 2 & 25.0 & 3 & 13.6 & & 1 & 6.3 & 5 & 35.7 & \\
\hline Illiterate & 4 & 50.0 & 10 & 45.5 & & 6 & 37.5 & 2 & 14.3 & \\
\hline Primary education & 0 & 0.0 & 2 & 9.1 & & 4 & 25.0 & 3 & 21.4 & \\
\hline \multicolumn{11}{|l|}{ Occupation } \\
\hline Employee & 4 & 50.0 & 4 & 18.2 & \multirow{4}{*}{0.189} & 0 & 0.0 & 4 & 28.6 & \multirow{4}{*}{0.003} \\
\hline Student & 0 & 0.0 & 2 & 9.1 & & 0 & 0.0 & 0 & 0.0 & \\
\hline Farmer & 4 & 50.0 & 11 & 50.0 & & 14 & 87.5 & 4 & 28.6 & \\
\hline House wife & 0 & 0.0 & 5 & 22.7 & & 2 & 12.5 & 6 & 42.9 & \\
\hline
\end{tabular}

Chi-Square Tests *statistically significant difference at P. value $<0.05$, **statistically significant difference at $P$. value $<0.01$

Table (1): Shows that half of control group (50\%) their age more than 40 years compared to $(70 \%)$ in the study group . regarding to gender, it was found that majority of control group (86.7\%) were male compared to $(73.3 \%)$ in study group . it was found that the highest percentages in both groups (study and control) were married and farmer. Regarding education, it was found that more than one quarter (26.7\%) in both groups were secondary education.

Table (2): As regard causes of ankle fracture, it was found that more than half $(53.3 \%)$ of control group had accident while more than half (53.3\%) of study group had falls. As regard affected side, it was found that more than half $(53.3 \%)$ of control group their affected side was right and more than two third $(73.3 \%)$ of study group was left side. Regarding chronic diseases (30\%) of study group had hypertension while $(10 \%)$ of control group had diabetes. As regard neurostatus, it was found vast majority of control group (90\%) had pain compared to more than two fifth $(46.7 \%)$ in study group.
Figure (1): Showed that more than two third (73.3\%) of control group had medial ankle fracture compared to more than two fifth (46.7\%) in study group.

Table (3): Shows that in lateral wound ,it was found that one quarter $(25 \%)$ of control group had normal healing and more than two fifth $(46.8 \%)$ in study group . regarding other complications, it was found that 8 patients of control group had residual pain and 4 patients in study group. In medial wound healing it was found that more than one third (36.4\%) of control group had normal healing while majority $(85.7 \%)$ in study group. As regard other complications, it was found that 10 patients of control group had residual pain and 9 patients in study group. There was 7 patients from control group had infection, 4patients had deformity and 2 had Malunion. There was statistically significant difference between study and control in ankle fracture medial wound.

Table (4): Shows no significant difference between ankle fracture wound type and demographic data for both groups. 


\section{Discussion}

Ankle fractures are one of the more commonly occurring forms of trauma managed by orthopedic teams worldwide. The impacts of these injuries are not restricted to pain and disability caused at the time of the injury but the long-term consequences may also be physical, psychological and social McLean et al., (2013).

Open reduction and internal fixation (ORIF) represents the gold standard for the treatment of ankle fractures to restore anatomical alignment and articular congruity of ankle mortise to avoid altered loading of the tibiotalar joint and subsequent poor functional outcomes Armando et al., (2018)

\section{Part 1: Demographic and medical data}

Demographic characteristics like age, gender, occupation has imperative part in causation of ankle fractures which may indeed influence their recuperation after the surgery. Regarding to age the current study revealed that, more than one third of the sample was more than 40 years old, this result in agreement with Armando et al., (2018) they expressed that majority of research sample mean aged was 47.2years.In the same line Robiaetal., (2017) found that mean age of the participants was 50 years in their study. Korim et al. ,(2014) state that a mean age of studied sample were 42.4 years, also Loretta et al .,(2018) state that the average age was41 years.

According to gender the current study refers to, the majority of the study was males, More over Armando et al., (2018) \& Korim et al., (2014)stated that the majority of their study was male. The result negated with Black et al., (2013) who mention that ankle fractures are more frequent among females, Females generally have an increased incidence during their life, mainly between the ages of 30 and 60, high prevalence of low-energy trauma among women, and increased incidence of osteoporotic fractures with age. Another way this result contradicted the results by Robiaetal., (2017) who reported that; more than half of their study was female.

Regarding education, it was found that more than one quarter $(26.7 \%)$ in both groups were secondary education Robiaet al .,(2017) found lower education were common. Songet al., (2018) found primary education were common. The study results revealed thathighest percentages in both groups (study and control) were married and farmer. Linet al., (2012) agreed with these findings that the majority of study sample were manual worker.

Based on the result of the current study, regarding tocauses of ankle fracture, it was found that more than half of control group had accident while more than half of study group had falls, Juto et al. , (2018)demonstrated that ankle fractures caused by traffic accident, fall from heights, and crushing injury. McLean et al. , (2013) revealed that most common causes of ankle fracture were bike accident, fall and twisting motion. Sun et al., (2018) \& Stäbler et al., (2012) stated that the majority of ankle fractures were caused by low-energy injury. In this study the lowenergy trauma was described as a fall from a standing height or less, with an eventual physical activity not more than walking. The remaining fractures, including sports injuries and falls down stairs, were defined as non-low-energy trauma.

The findings of the current study revealed that more than half of control group their affected side was right and more than two third of study group was left side.

Bugler et al., (2012) stated that Left side was commonly affected in their study, while Steven et al., (2012) found the right ankle was common.

Regarding chronic diseases. Less than one third of study group had hypertension. Peteret al., (2009) revealed that hypertension seem to be the major cardiovascular risk factor for fractures.

As regard neurovascular assessment, it was found that the highest percentages in both groups normal color, moderate swelling. Weak pulse, warm temperature, more than one quarter of control group have early capillary refill compared to majority in study group, vast majority of control group had pain compared to more than two fifth in study group. These results agreed with. Stein et al.., (2012). Postoperative pain is associated with extended post-anesthesia care unit stay in the ambulatory surgery patients; an increased rate of unanticipated admission or readmission after surgery, and increased cost. McLean et al., (2013) stated that a broad range of physical impacts were described by both patients and health professionals. These impacts included mechanical elements (swelling, reduced muscle strength, decreased range of motion) and associated afferent impacts (pain, discomfort, altered sensation). Pain was the main complain reported by patients.

Regarding type of ankle fracture wound more than two third of control group had medial ankle fracture compared to more than two fifth in study group, another way this result contradicted the results by Loretta et al.,(2018) who stated that isolated lateral malleolus fractures was the commonest fracture .In the same line Armando et al .,(2018) found that Bimalleolarfractures were the most frequent ankle fracture followed by isolated medial and isolated lateral fractures, Polzer et al .,(2012)The majority of patients reported having lateral fractures.

Regarding other complications, it was found that mostcomplicationswere residual pain followed by infection, deformity and Malunion Armando (2018) stated that most commonpostoperative complication in their study were residual pain, infection and 
wound dehiscence are common postoperative complications of ankle fracture. Ovaska , (2015)Explained that postoperative residual ankle pain is also often associated with chondral damage and soft tissue impingement, as well as posttraumatic neuromas, arthrofibrosis, malediction, loss of reduction, and Malunion. Jun \& Xuecheng, (2017) stated that the number of patients withwound complications is also increasing. It was reported that the incidence rate of wound infections is from 5\% to 25. Forpatients who are diagnosed with superficial infections, a good outcome can be achieved after active treatment. However, it isdevastating to patients who are diagnosed with deep infections.

In the same line Zalavraset al., (2009) added that infection is a recognized complication in the operative management of ankle fracture. The rate of deep infection in patients undergoing ORIF of AF ranges from $1 \%$ to $8 \%$ predisposing factors include advanced age, high energy injuries, smoking, diabetes, open fractures, compromised soft tissue envelope and alcoholism.

Regard relation between types of ankle fracture wound and demographic data this study illustrated that there was no significant difference between type of ankle fracture wound and demographic data Taweel et al., (2013) revealed thatno relation between theclasses of ankle fractures, age and gender as well asthe energy involved in the trauma.

\section{Conclusion}

The present study revealed that providing patients with a guide detailed instructions for patient with ankle open reduction internal fixation surgery was represented of great value in wound healing and reduction other complications (residual pain, Malunion, infection, deformity).

\section{Recommendation}

Providing copy of the nursing instructions forpatients with ankle open reduction internal fixation surgeryin the trauma units and out patients'clinic of orthopedic to be readily available for all patients with ankle fracture, the present study should be replicated on larger study populations for generalization of the results.

\section{References}

- Armando, M., Christian, C., Luigi, S., Massimo, I., (2018): Postoperative Complications and Reoperation Rates Following Open Reduction and Internal Fixation of Ankle Fracture, Joints, Vol. 6 No. 2

- Black, E., Antoci, V., Lee, T., (2013): Role of preoperative computed tomography scans in operative planning for malleolar ankle fractures.
Foot \& ankle international, American Orthopaedic Foot and Ankle Society [and] Swiss Foot and Ankle Society, Vol $34, \mathrm{p}$ 697-04.

- Bugler, K., White, T., \& Thordarson, B., (2012): Focus on Ankle Fractures, The Journal of Bone and Joint Surgery, Vol 94, pp (1107-1112)

- David, L., (2019): Ankle Fracture Surgerythe American Orthopedic Foot \& Ankle Society (AOFAS) https://www.footcaremd.org/conditionstreatments/ankle/ankle-fracture-surgery

- David, L., Naomi, S., (2019): ankle surgery, American Orthopedic foot \&ankle Society, Orthopedic Foot and Ankle Foundation https://emedicine.medscape.com/article/1946201overview

- Jun, S., Xuecheng, C., (2017): Risk factors of wound infection after open reduction and internal fixation of calcaneal fractures,Medicine Vol $96, p$ 44

- Juto, H., Nilsson, H., Morberg, P., (2018): Epidemiology of Adult Ankle Fractures: 1756 cases identified in Norrbotten County during 2009-2013 and classified according to AO/OTA, BMC MusculoskeletDisord Journal, Vol ;19(1):441. Published 2018 Dec 13. doi:10.1186/s12891-0182326-x

- Korim, M., Payne, R., Bhatia, M., (2014): casecontrol study of surgical site infection following operative fixation of fractures of the ankle in a large U.K. trauma unit. Bone Joint J, Vol96, p (5), No 636-40. doi: 10.1302/0301-620X.96B5.33143..

- Kortekangas, T., Haapasalo, H., Flinkkilia, T., (2019): three week versus six week immobilization for ankle fracture, non-inferiority clinical trial : 364 : 432

- Lin, C., Donkers, N., Refshauge K., Beckenkamp P., Khera K., \& Moseley A., (2012): Rehabilitation for Ankle Fractures in Adults. Cochrane Database of Systematic Reviews, VOL 11, Article ID: CD005595.

- Loretta , B., Emily, L., Ariel, A., Rosanna, D., Sophia, E., Anderson, B., Alex, H., Kenneth, J., (2018): Postoperative Pain After Surgical Treatment of Ankle Fractures: A Prospective Study JAAOS Global Resarch Review, Vol 2 p 9 e 021

- Macera, A., Carulli, C., Sirleo, L., Innocenti, M., (2018): Postoperative Complications and Reoperation Rates Following Open Reduction and Internal Fixation of Ankle Fracture. Joints. 2018; 6(2):110-115. Published 2018 May 21. doi:10.1055/s-0038-1653949

- McLean, S., Moffett, J., Sharp, D., Gardiner, E., (2013): A randomised controlled trial comparing graded exercise treatment and usual physiotherapy for patients with non-specific neck pain, Vol 18, pp(199-205). doi: 10.1016/j.math.2012.09.005. 
- Mehta, S., Rees, K., Cutler, L., Mangwani, J., (2014): Understanding risks and complications in the management of ankle fractures. Indian J Orthop. 2014; 48(5):445-452. doi:10.4103/0019. 5413.139829

- Mikko, O., (2016): complications in ankle fracture surgery, Acta orthopedic supplementum no 358, Volume 86,Doctoral thesis, University of Helsinki

- Nursing Alliance for Quality of Care (NAQC), (2013): Fostering successful patient and family engagement, American nurse , Vol 9 , pp (2):1-4

- Ovaska, M., (2015): Complications in ankle fracture surgery. Acta OrthopSuppl, Vol 86 , No 358, Doctoral Thesis , University of Helsinki DOI: 0.3109/17453674.2014.1002273p(22):e167. doi: 10.2106/JBJS.K.01706.pain management of orthopaedic patients, J Bone Joint Surg, Vol 21

- Peter, V., Lars, R., Leif, M., (2009): Hypertension Is a Risk Factor for Fractures: a nationwide casecontrol study. J Hypertension 24:581-589

- Polzer, H., Kanz , K., \& Pranz W., (2012): Diagnosis and Treatment of Acute Ankle Injuries: Development of an Evidence-Based Algorithm. Orthopaedic Review, Vol 2, p (4-5). doi: 10.4081/ e5. http://dx.doi.org/10.4081/or.2012.e5)

- Punder, R., (2005): Nursing the surgical patient $2^{\text {nd }}$ (ed) Edinburgh London New Yourk Oxford Philadelphia St Louis Sydney Toronto. PP (4 : 61 , 233 : 263).

- Robia, R ., Cornelis, H., van der, V., Berry, I., Ruud W., Steven E., \& Tim H., (2017) :High Prevalence of Chronic Pain With Neuropathic Characteristics After Open Reduction and Internal Fixation of Ankle Fractures Foot, Ankle International journal, Vol. 38 , p (9) 987-996.

- Song, L., Yanbin, Z., Wei, C., Lin , W. , Xiaolin, Z., Yingze, Z., (2018): Demographic and socioeconomic factors influencing the incidence of ankle fractures, a national population-based survey of 512187 individuals, Scientific Reports | Vol 8 , p10443 | DOI:10.1038/s41598-018-28722-1

- Stäbler A., Szeimies U., Walther M., (2012): Foot and Ankle Sports Orthopedics, RadiologischeDiagnostik des Fußes. Stuttgart, p 154

- Stein, B., Srikumaran, U., Tan, E., Freehill, M., Wilckens, J., (2012): Lower-extremity peripheral nerve blocks in the perioperative

- Steven, M., Joel, D., Julie, C., Terry, P., (2012): Life impact of ankle fractures: Qualitative analysis of patient and clinician experiences , BMC Musculoskeletal Disorders, vol13, No 224 doi:10.1186/1471-2474-13-224

- Sun, R., Li , M., Wang, X., Li, X., Wu, L., Chen, Z., Chen, K., (2018): infection after open reduction and internal fixation of ankle fracture $\mathrm{A}$ retrospective multicenter study, Medicine, Vol 97: p 86-91doi: 10.1016/j.jisu...10.002

- Sun, Y., Wang H., \& Tang Y., (2018): Incidence and risk factors for surgical site infection after open reduction and internal fixation of ankle fracture: A retrospective multicenter study. Medicine (Baltimore). 2018; 27(7):e9901. doi:10.1097/MD.0000000000009901

- Taweel, N., Raikin S., Karanjia H., \& Ahmad J., (2013): The Proximal Fibula Should Be Examined in All Patients with Ankle Injury: A Case Series of Missed Maisonneuve Fractures, The Journal of Emergency Medicine, Vol 44, pp(251-255). http://dx.doi.org/10.1016/j.jemermed.2012.09.016)

- Todd, M ., (2015): Ankle Joint Anatomy,Vol 33, No (3),PP 888-894

- Unnithan, S., Thomas J., (2018): Not all ankle injuries are ankle sprains - Case of an isolated cuboid stress fracture. Clin Pract.;8(3):1093. Published 2018 Jul 10. doi:10.4081/cp.2018.1093

- Van den berg C., Haak T., Weil N., Hoogendoom J., (2018): functional bracing treatment for stable weber type B ankle fractures, 49:1607

- Zalavras, C., Christensen, T., Rigopoulos, N., Holtom, P., Patzakis, M., (2009): Infection following operative treatment of ankle fractures, ClinOrthopRelat Res, Vol 467,p 1715-20doi: 10.1007/s11999-009-0743-8. 